April 2013

\title{
In Search of Professional Dispositions that Yield Cultural Relevance in Primary Grade Pedagogy: A Cautionary Tale of One Kindergarten Teacher
}

\author{
Patricia L. Marshall Ed.D. \\ NC State University, patricia_marshall@ncsu.edu \\ Jessica T. DeCuir-Gunby Ph.D. \\ NC State University, jessica_decuir@ncsu.edu \\ Allison W. McCulloch Ph.D. \\ NC State University, allison_mcculloch@ncsu.edu
}

Follow this and additional works at: https://digitalscholarship.unlv.edu/jpme

\section{Repository Citation}

Marshall, Patricia L. Ed.D.; DeCuir-Gunby, Jessica T. Ph.D.; and McCulloch, Allison W. Ph.D. (2013) "In

Search of Professional Dispositions that Yield Cultural Relevance in Primary Grade Pedagogy: A

Cautionary Tale of One Kindergarten Teacher," Journal of Praxis in Multicultural Education: Vol. 7: No. 1, Article 3.

DOI: 10.9741/2161-2978.1046

Available at: https://digitalscholarship.unlv.edu/jpme/vol7/iss1/3

This Article is protected by copyright and/or related rights. It has been brought to you by Digital Scholarship@UNLV with permission from the rights-holder(s). You are free to use this Article in any way that is permitted by the copyright and related rights legislation that applies to your use. For other uses you need to obtain permission from the rights-holder(s) directly, unless additional rights are indicated by a Creative Commons license in the record and/ or on the work itself.

This Article has been accepted for inclusion in Journal of Praxis in Multicultural Education by an authorized administrator of Digital Scholarship@UNLV. For more information, please contact digitalscholarship@unlv.edu. 


\title{
In Search of Professional Dispositions that Yield Cultural Relevance in Primary Grade Pedagogy: A Cautionary Tale of One Kindergarten Teacher
}

\author{
Abstract \\ Primary grade teachers are challenged to establish firm learning foundations for all children, yet for many \\ teachers cultural diversity makes this a complex pedagogical challenge. It is widely assumed that the \\ success with which teachers meet this challenge is reflected in their dispositions toward diversity, and \\ ultimately toward culturally relevant pedagogy as a professional orientation. This article describes a multi- \\ year study of cultural relevance in early mathematics teaching. Using the case of one kindergarten \\ teacher who exhibited positive dispositions toward cultural relevance, the authors examine factors that \\ seemed to work against its adoption in her pedagogy.

\section{Keywords} \\ Cultural pluralism; Culturally relevant pedagogy; Early mathematics; Mathematics - Study and teaching \\ (Primary); Multicultural education; Professional development; Teachers - Training of

\section{Cover Page Footnote} \\ The research was supported by a grant from the National Science Foundation (Award \# 0353412). Any \\ opinions, findings, and conclusions or recommendations reported herein are those of the authors and do \\ not necessarily reflect the views of the National Science Foundation.
}


In SEARCh of Professional Dispositions that Yield Cultural Relevance In PRimary Grade PEDAgogy: A Cautionary TAle OF ONE KINDERGARTEN TEACHER

Scholars contend that to promote academic success and firm learning foundations for all children, contemporary primary teachers need to acquire knowledge of the impact of culture on the teaching-learning process. Yet converting such knowledge into effective instructional practice can represent a considerable challenge even for teachers who may hold the requisite professional dispositions to do so. In this paper we examine the case of one such teacher who participated in our multi-year professional development research project that explored how K2 teachers understand, make sense of, and ultimately enact culturally relevant pedagogy. We begin by describing the study's conceptual framework and methodology. Next we discuss our findings by contrasting the case study teacher's requisite dispositions with her enacted pedagogy. Finally, we examine challenges the notion of requisite dispositions presents for promoting cultural relevance in primary pedagogy.

Cultural Relevance In Primary Pedagogy: Toward Promoting Deep UNDERSTANDING IN K-2 MATH

The project, Nurturing Mathematics Dreamkeepers (NMD), was a longitudinal professional development research study designed to explore how K-2 teachers understand and adopt standards-based teaching practices (National Council of Teachers of Mathematics, 2000) that have potential to promote young children's deep understanding of early mathematics concepts. Two ideas (i.e., standardsbased mathematics teaching and cultural relevance) formed the base of the NMD conceptual framework. Both are theoretically grounded in social constructivist conceptions of the teaching-learning process (Kincheloe, 2005; Palincsar, 1998); thus, NMD supported the notion that teachers need to acquire critical understanding of the socio-cultural contexts in which children develop as well as the manners in which outside-of-school realities impact children's learning in schools.

\section{WHAT IS STANDARDS-BASED MATHEMATICS TEACHING?}

Standards-based teaching refers to practice that is consistent with goals set forth by the National Council of Teachers of Mathematics (NCTM) in the document Principles \& Standards for School Mathematics (NCTM, 2000). The NCTM Standards state that teaching "requires understanding what students know and need to learn and then challenging them and supporting them to learn it well" (p.16). They were a call for teaching mathematics with a goal of promoting deep understanding for all students. Further, NCTM emphasized the importance of 
providing opportunities to develop understanding for "all students" by the inclusion of the Equity Principle, which adds that teachers must include "high expectations and strong support for all students" (p.12).

In general standards-based teaching characterizes teachers who operate from the assumption that a student's mathematical reality is not independent of that student's ways of knowing and acting. This implies that what a student sees, understands, and learns is constrained and afforded by what that student already knows, and that mathematical learning is a process of transformation of one's knowing and ways of acting (Simon, et al., 2000, p. 584). Franke, et al. (2007) note that support for such learning "comes from knowing the students, the situation, and the content and then making decisions that support interaction that productively engages students in moving their ideas forward" (p. 228). In standards-based practice, the Equity Principle is not an add-on; instead, it is central to all pedagogical moves (Hiebert et al., 1997). Practice that is consistent with standards-based goals provides equitable opportunities for all students in all aspects of classroom interactions. It requires that teachers convey a fundamental respect for individual students, what they bring to the classroom, and what their individual contributions can add to their peers' mathematical understanding (Hiebert et al, 1997).

\section{Cultural Relevance in the Teaching-Learning Process}

A key premise of NMD was that in order to enact standards-based mathematics teaching, the teachers needed to understand culture as a facet of the teachinglearning process. Culture was defined as "the consistent ways in which people experience, interpret, and respond to the world around them" (Marshall, 2002, p. 8) including the tendencies or orientations commonly exhibited in academic contexts by students from the same cultural/ethnoracial community. Scholars identify culture as fundamental to the broader schooling enterprise and they have called upon educators to adopt critical professional orientations, such culturally relevant pedagogy or culturally responsive teaching, that reflect understanding and appreciation of its impact (e.g., Gay, 2002; Giroux, 2005; hooks, 1994; Kincheloe, 2005; Ladson-Billings, 1994; Marshall, 2002).

According to Ladson-Billings (1994) there are three primary tenets of culturally relevant pedagogy: high academic achievement, cultural competency, and sociopolitical consciousness. Through adoption of cultural relevance a teacher establishes a success ethos in the classroom that "allows ... students to choose academic excellence yet still identify with their ... culture" (p. 17). Correspondingly, Gay (2002) reported that culturally responsive teaching involves "using the cultural characteristics, experiences, and perspectives of ethnically diverse students as conduits for teaching them more effectively" (p. 106). Five "essential components" of cultural responsiveness (i.e., knowledge base about cultural diversity, curriculum content expansion, caring, effective 
interpersonal interactions and communications, and diverse instructional delivery systems) mesh with the three tenets of culturally relevant pedagogy and together they delineate what teachers need to know and do in order to adopt this critical professional orientation.

Teachers who effectively promote high academic achievement, for example, must use an array of resources and presentation formats that align with students' unique learning styles or tendencies. Tailored to the needs and experiences of the particular students, culturally relevant (CR) instruction in one classroom may look quite different from that in another classroom. Even so, all teachers whose pedagogy exhibits CR find ways to incorporate students' outside of school cultural realities into instruction thereby enhancing students' interest in and success with academic content. Hence, CR instruction is "... based on the assumption that when academic knowledge and skills are situated within the lived experiences and frames of reference of students, they are more personally meaningful, have greater interest appeal, and are learned more easily and thoroughly" (Gay, 2002, p. 106).

While cultural competency as a second component of CR represents teachers' abilities to "capitalize on the cultural practices and sensibilities of their students" (Nasir, et al., 2008, p. 219), it also represents teachers' introspective capacities to acknowledge themselves as cultural beings. Teachers who embrace $\mathrm{CR}$ recognize that without constant vigilance (via reflection on the subjectivities they bring to teaching), it is possible to inadvertently diminish academic learning for different students through the teachers' own actions. Finally, sociopolitical consciousness in CR relates to teachers' orientations toward status, resource, and power differentials among diverse groups in society and the impact on students in schools. Teachers who adopt $\mathrm{CR}$ recognize that race, class, and gender, more commonly than not, still do matter in who gains access to high quality schooling (Noguera, 2001; Orfield \& Lee, 2006). As such these teachers strive to create and maintain equity in their classrooms through building coalitions with other teachers, parents, and students themselves that help counteract the negative impact of disparities and inequities in the larger society.

\section{NMD PRoJeCt METhodology: CONTEXT OF THE CASE StUdy}

The larger NMD project employed a quasi-experimental design through which three intervention groups and one control group of K-2 teachers were established. Intervention groups were organized into "cohorts" (composed of teachers from different schools). Cohort I teachers participated in the study for three years, 
while Cohorts II and III participated for two years and one year respectively. Each cohort received approximately 90 hours of professional development (the study intervention) delivered via four 2-day retreats held on the university campus over the course of each project year. The control group did not receive an intervention. Retreats were structured for teachers to explore the "big ideas" in K-2 mathematics along with the tenets of CR teaching and three related sub-skills (i.e., language matching, cultural connecting, and communalizing ${ }^{1}$ ). Each cohort teacher received a $\$ 1,000$ stipend per year of participation, school district professional renewal credits, and if desired, support for National Board Certification.

\section{PROJECT PARTICIPANTS}

A total of 65 female teachers from 7 different elementary schools (6 intervention; 1 control) in a large urban district participated in NMD. Schools that met the selection criteria $^{2}$ (rather than individual teachers) were solicited to participate. Within each school pairs of teachers were organized as "buddies" or professional peers. Buddies were required to observe each other's mathematics lessons and participate together in post-teaching reflections. Data reported in this article focuses on one Cohort II teacher from Rhine River Elementary named Aisha ${ }^{3}$.

\section{DATA Sources, DATA Collection, \& DATA ANALYSiS}

A case study approach was chosen in order to illustrate the nature of Aisha's dispositions toward cultural relevance and to highlight factors that appeared to militate against its incorporation into her professional practices and reflections. Utilizing a case study approach allowed us to focus on both a real-life event and its context through examination of a variety of data sources (Yin, 2004). And although Aisha worked with two buddies, they are not included in this case as neither exhibited dispositions comparable to hers. During the two years she participated in our study, Aisha attended approximately $95 \%$ of the retreats, participated in 3 different one-on-one interviews, taught 16 different videotaped

\footnotetext{
${ }^{1}$ Cultural referencing occurred when teachers made direct or indirect reference to specific element(s) of child's culture/background (e.g., language, home experience, etc.) to enhance understanding. Language matching occurred when teacher employed child's own language (rather than or in addition to standard mathematics language) in directions, explanations, or follow up to child's comments. Communalizing occurred when teacher gave an instructional prompt/directive to children to link their own success with that of their peers.

${ }^{2}$ Criteria included Title I designation, a diverse student population, at least 3 teachers at each of the targeted grade levels for the study, and a documented achievement gap between Black and White students based on school district assessment.

${ }^{3}$ Teacher and school names are pseudonyms.
} 
mathematics lessons, and engaged in 8 different videotaped post-teaching reflection sessions. She also participated in 1 focus group conversation. In creating the case, we analyzed retreat artifacts, one-on-one interviews, classroom lessons, research assistant's (RA) field notes, videotaped post-teaching guided reflection sessions, and a post-intervention focus group conversation.

RETREAT ARTIFACTS. Each year of the study, the intervention teachers participated in the project intervention (NMD "retreats"), which focused on mathematics, culture, and general pedagogy. Products from some retreat sessions such as the mathematics and cultural autobiographies and the teaching selfreflection activity represented NMD artifacts. These separate artifacts were analyzed using the analysis of narratives approach that involves examining data to identify common themes across cases (see Polkinghorne, 1995).

VideotAPED MATHEMATics Lessons. Each teacher was videotaped teaching mathematics on 8 separate occasions (i.e., 2 consecutive lessons twice in the fall and twice in the spring) each year of the study. Lessons focused on the normal mathematics course of study content required in primary grades by the school district, and all were analyzed using a three-phase process: mapping, rubric coding, and transcription of verbal communication from the lesson rubric. Mapping a lesson involved providing descriptions of its structure with a focus on the teachers' classroom interactions (Stigler, et al., 1999). The mappings were used to help describe each teacher's actions during individual mathematics lessons. Next, through rubric coding, the second phase of lesson analysis, we tracked teacher-initiated verbal communication with a focus on phrasing used by the teacher that alluded to any of the CR tenets or sub-skills. The rubric was also used to track teachers' efforts to highlight, clarify, and/or utilize children's mathematical thinking during lessons. Once we identified an example of the targeted phrasing types, we tallied the frequency of occurrence within two-minute intervals. After each lesson was tallied, the verbal communication represented by each tally was transcribed verbatim.

InTERVIEWS, REFLECTION SESSIONS, \& Focus GRoups. Teachers participated in three different data yielding discussion-type activities. The first were one-on-one semi-structured interviews (Rubin \& Rubin, 2005) conducted at the beginning and end of each school year. Interviews lasted 30 minutes to one hour, and were conducted by a trained research assistant (RA) at free periods before, during, or after regular instructional hours. Second was the post-teaching guided reflection sessions facilitated by a trained RA. Typically, these sessions were scheduled 2-4 days following two consecutive lessons for each teacher in a buddy pair (four lessons total) and consisted of the two teachers discussing their own and each 
other's mathematics teaching. Depending on the verbosity of the teachers, reflections lasted $1 \frac{1}{2}$ to 2 hours. The third activity was the focus group "conversations" which occurred approximately one year after completion of the formal data collection phase of the study. Data from these activities were analyzed separately using thematic content analysis (Coffey \& Atkinson, 1996). We created separate codebooks for each type using both theoretical (based on the NMD conceptual framework themes) and data-driven codes (see DeCuir-Gunby, et al., 2011). For each codebook, we examined the relationships between the codes, theory, and our research study goals (Coffey \& Atkinson, 1996).

\section{FINDINGS: THE CASE OF AISHA}

At the time she joined NMD, Aisha was a 36-year old African American woman who had nearly 14 years of professional experience in the field of education and a master's degree in adult education with a focus on diversity training. During the two years she participated in the study Aisha was a kindergarten teacher at Rhine River Elementary, a school that included NMD teachers from all three cohorts. The student population at Rhine River was $66.9 \%$ White, $15.8 \%$ African American, and $10.3 \%$ Latino/Hispanic. Approximately $8 \%$ of the overall student population did not speak English as a first language and $25 \%$ were eligible for free or reduced-price lunch. Rhine River had two principals over the course of its participation in the study. Both were enthusiastic about and highly supportive of the teachers from that school who participated in the project.

Although at the time of the study Aisha was teaching kindergarten, earlier in her career she had taught 4th and 7th grades. Also, she had once been a literacy coach wherein her duties included making professional presentations to other teachers about incorporating diversity into literacy instruction. As the only child of college educated parents, Aisha sprang from a solidly middle class background. Well into her adulthood both of her parents worked in higher education. Aisha has a natural flair for the comical and she interacted easily with us (as co-PIs of the research), the rest of the NMD research team, and the other teachers in the study. She also has a penchant for directness so, on multiple occasions, Aisha shared that the CR focus of the study had not been the main draw for her in joining NMD. For example, during the post-intervention focus group conversation, Aisha noted, “... it wasn't the culture piece I struggled with. I struggled with the math piece”. Throughout her participation in the study, Aisha offered numerous insights about cultural diversity issues revealing that she had considerable knowledge of the topic.

\section{A STAND-OUT IN THE CROWD}

Over the span of the study we received feedback from many of the teachers about the complexity and the applicability of the ideas explored during the retreats. 
Depending on its nature we interpreted such feedback as a sign of the intellectual challenge of a particular retreat session, yet we also perceived it as an indication albeit imprecise of the teachers' receptivity (or resistance) to the NMD assumptions about standards-based mathematics teaching and the place of culture therein. Thus, to some extent feedback offered insights into dispositions (e.g., beliefs, attitudes, and professional inclinations) toward CR, and the likelihood that particular teachers would (or would not) incorporate it into their mathematics instruction and post-teaching reflections.

Based on the feedback we received from Aisha, we held no reservations about her receptivity to $\mathrm{CR}$ as a pedagogical orientation. This was mainly because Aisha consistently offered evidence of what we called "requisite dispositions" that were clearly in alignment with the CR orientation. During the two years she participated in the study, Aisha expressed awareness and appreciation of the complexities of cultural diversity and its impacts on the teaching-learning process that surpassed all but a few of the other NMD participants. Consequently, we expected to find multiple references to the tenets and sub-skills of CR in Aisha's post-teaching reflections if not in her actual instructional practices.

\section{EVIDENCES OF REQUISITE DISPOSITIONS}

Our impressions of Aisha were based on evidences she presented during project retreat activities along with information she shared about her personal and professional backgrounds. Her rich early exposure as a child to diversity seemed complemented by her graduate degree focus on diversity. This alone contrasted sharply with most of the other NMD teachers whose exposure to diverse others was limited, and/or who had scarcely examined the topic during their preprofessional preparation. Aisha's positive disposition toward diversity was illustrated in retreat artifacts and ideas she shared during retreat sessions. In her cultural autobiography, for example, Aisha reported that her upbringing had set the stage for her attitude toward diversity.

I have had the fortune of being in diverse groups of friends since elementary school. I was invited and did go spend the night at white people's houses. When I got to middle school my group of friends was a tight knit cluster of 3 black girls and 2 white girls. We took turns spending Friday nights at each other's house[s]. Those times are invaluable!!!

Assessing the impact of her early exposure to diverse others on her current professional stance, Aisha noted, "I don't have any apprehensions about participating in conversations about cultural diversity as it relates to [the] teaching-learning process. I developed the comfort long ago during my adolescent years!" Indeed, unlike many of the other teachers, from the outset Aisha exhibited no signs of "cultural aversion" in relation to so-called controversial topics (e.g., stereotypes, aversive racism). According to Irvine (1990) many teachers avoid 
such topics for fear that addressing them will upset the cross-racial harmony they perceive exists in schools. Aisha attributed her comfort with such topics, in part, to her personality and to the fact that as a child she interacted with students who attended the university where her mother was on staff. She noted,

I know that I [am] the teacher I am because of the natural affinity that I have for people of other cultures and my love of learning! My mother has traveled to every continent except Antarctica. She has an affinity for the international students at [university name]. I never knew who she was going to bring home. We have had students from India, Africa, and Hungary at our home on several occasions.

Whether in large group discussions or small group activities, Aisha did not hesitate to express opinions about the importance of teachers' attending to cultural diversity through their teaching strategies, instructional resources, and general professional demeanor. The seeming ease with which she engaged others was particularly on display during a retreat activity and discussion about ethnoracial identity development (Helms, 1993; Phinney, 1993). When a friend and Rhine River colleague (another African American teacher) acknowledged personal challenges resulting from a life-long struggle with the devaluation of racial blackness, Aisha urged her friend to consider the impact an African American teacher's own identity struggle could present for young African American students. Later, both teachers revisited this issue during the focus group conversation comprised of all African American teachers and led by the lead author who is also African American ${ }^{4}$. Asked to share reflections on noteworthy issues from the NMD project, Aisha's friend recalled the identity development discussions as being particularly impactful; another teacher cited the "culture piece" overall as having been critical. Aisha replied that although she has considerable interest in multicultural issues, math (rather than culture) had been the challenge for her in the NMD project. She inserted the coda, "I already know I'm black, I already know there's a struggle.... . I was already comfortable with who I was...". The other teachers did not seem to interpret this comment as a put down of them, nor was Aisha seen as boastful. We surmise this may have been owing to Aisha's jocular nature along with the context and timing of her contributions.

Other insights we gained about Aisha's dispositions came from descriptions she provided of her experiences as a student and as a teacher. For example, she detailed how race and economic class impacted the manner in which teachers responded to her as a middle school student.

\footnotetext{
${ }^{4}$ In addition to the group in which Aisha participated, there were two other post-intervention group conversations. One was comprised of all White teachers and the other was multi-racial.
} 
Unfortunately, I had a white math teacher who proved to be not only a racist, but an elitist too! [Teacher's name] taught advanced math and she sent [a] very clear message to me DAY 1 . When I walked in she said "Are you sure you are in the right room?" Then she went on to say "You'll never receive anything higher than a $\mathrm{C}$ in my class!" I had yet to put pencil to paper. Thank God that I had [names two other teachers] in the same year to help me stay positive. .... 7th and 8th grade years no African American teachers. For the most part I enjoyed all of the teachers and I felt like they related to me because of my middle class background, but not necessarily my race.

Herein Aisha exhibited awareness of the multi-dimensionality of diversity in schools as well as an understanding that the challenge of CR extends beyond issues of race. Likewise, in her professional self-image, taken from her mathematics autobiography essay, Aisha seemed to recognize that adopting CR demanded she attend to the needs of all her students.

As a teacher of kindergarten students, I feel confident in my abilities as a math teacher. The lessons are interactive and fun! The repetition of reviewing concepts in different ways allows all of my student's opportunities to learn! .... I am a good math teacher because I don't teach to the middle. The students who are struggling can ask questions without me thinking something is wrong with them. Many times the math teachers in the past had the attitude that math is exact! There is only one answer and why can't you get it right!

Our broad interpretation is that the requisite dispositions Aisha exhibited manifested through her openness, if not eagerness, to examine critical issues including implications of teachers' expectations for children of color. She seemed to recognize the difference between mere awareness of cultural diversity versus adopting a pedagogical orientation with potential to result in substantive positive learning experiences for students in schools. Drawing on her cultural autobiography, we note Aisha's unprompted attention to exploring controversial issues and professional beliefs/practice congruence. She noted,

... educators will continue to do business as usual [in their teaching] until they are willing to have those uncomfortable discussions. Discussing diversity as it relates to teaching and learning is just the first step. Real change will not occur until the entire county or even the school began [sic] to apply what they learn to their everyday habits and plans.

She concluded this discussion with a "list of my beliefs about teaching". Items in Aisha's list are well aligned with culturally responsive teaching (Gay, 2002) and 
profiles of "star teachers of children in poverty" (Haberman, 1995). Aisha noted,

1. Every child can learn.

2. Every child has gifts and talents.

3. Any student I have on my roll is meant for me to have!!

4. Fair and equ[al] are not the same.

5. I am a professional and I will act accordingly.

Finally, in two different retreat sessions (approximately 6 months apart) Aisha completed a self-reflection activity in which she described how CR sub-skills were being incorporated into her mathematics teaching. Working independently, teachers were provided laptop computers to compose essays about CR in their own teaching. They were to select a mathematics concept they had taught very well as measured by their students' understanding, and provide examples of how /whether the three CR sub-skills (e.g., language matching, cultural connecting, and communalizing) had been incorporated. For both reflections, Aisha selected "patterns" as the concept she had taught especially well. Aisha described specific instances where she incorporated language matching with illustrations of how she affirmed children's home language usage that, according to Aisha, commonly diverted from standard mathematics terminology. In both essays, Aisha provided explicit examples of her use of language matching yet she readily acknowledged shortcomings in her pedagogy. For example, in her second essay she wrote

I haven't made any cultural connection relating to pattern blocks yet. ... I have at least four different cultures represented in my classroom. When we learn about different cultures through the study of the winter holidays around the world the children will have opportunities to make $3 \mathrm{D}$ patterns ... that include items from other cultures.

\section{DISCONNECTION, CONTRADICTION, \& INCONSISTENCY}

Our analysis of the school-based data sources revealed a much different image of Aisha from the one we gained through interactions with her during retreats and project activities. Gone was her astute insight on aligning instruction with the diverse needs and interests of students. In its place was an enacted pedagogy that showed scant evidence of Aisha's ability to convert her abundant knowledge of and appreciation for these and other components of CR into effective instructional practice. Most striking, however, was the lack of evidence of Aisha's ability to reflect critically and thoughtfully on the reasons behind her pedagogy. Various writers have reported that for many pre-service teacher candidates as well as inservice teachers, translating knowledge about cultural diversity into transformative classroom practice presents particular challenges (Brown, 2004; 
Hodge \& Cobb, 2010; Sleeter, 2008). We therefore expected some disconnection between the clear understandings Aisha articulated during project retreats and what occurred at her school site. Even so, we did not expect the extent of disconnection we found upon analyzing Aisha's post-teaching reflections and interviews.

As noted, Aisha was an experienced teacher who demonstrated more knowledge of CR (particularly the cultural competency and sociopolitical consciousness foci) than most of the other teachers in the study. Her understanding of contemporary schooling issues seemed to portend a more critical focus in her own instructional practice. Yet our analysis of video recordings of Aisha's actual teaching (juxtaposed with her comments about her lessons during post-teaching reflection sessions), revealed multiple contradictions and inconsistencies. Upon closer examination, we had to acknowledge that these findings represented apt if troubling examples of the analysis phenomenon known as initiation (DeCuir-Gunby, et al. 2012; Greene, et al., 1989; Rossman \& Wilson, $1985,1994)$ in which one data source contradicts or lacks consistency with another source. It was common for aspects of Aisha's interpretations of her teaching to differ markedly from the RA's as recorded through field notes during lessons, from what had been captured through the lesson rubric, and from what we observed in videotape playbacks of lessons.

For example, Aisha taught a 25-minute mathematics lesson on sorting and graphing. Based on lesson rubric tallies, we learned that in the first part of that lesson she engaged in whole class instruction with one instance of learning connecting or linking the current lesson to a previous lesson. She then distributed to the students a hands-on activity, which according to the RA's field notes, comprised individual bags of rings featuring Halloween characters as well as paper squares of assorted colors. Also featured were two graphs. Aisha instructed her students to sort and graph the items, and at the completion of the activity she led a whole class sharing session wherein individual students were instructed to present solutions on the whiteboard. Aisha concluded by briefly noting that the class would continue sorting for the next mathematics lesson. When asked about the purpose of the lesson (i.e., what her students were expected to learn through participation in the activity) during the post-teaching reflection session, Aisha's response seemed disjointed and largely misaligned with the videotaped lesson. She explained the purpose as follows:

They were supposed to learn, again, about one-to-one correspondence. Graphing - that the concept of graphing, that you start from the bottom, that you count the number one - that when you do kindergarten graphs, in the beginning the zero is not on the graph. They know what zero is. But zero is not on the graph at this time. So it just gives them a chance to do something interactive, and have an opportunity to count. And really understand one - also the representation of one or two. I had two rings, 
and so I will color two blocks. And just - there's a lot of abstract along with the concrete.

Drawing on this response, not only did Aisha's stated purpose lack clarity and evidence of instructional forethought, but it was inconsistent with the lesson she conducted. More important, however, is that Aisha offered no explanation for this obvious disconnection.

When we juxtaposed one-on-one interview data with videotaped lessons and post-teaching reflections, we discovered more contradictions, this time among Aisha's apparent interpretations of $\mathrm{CR}$, her actual teaching, and her reflections on her own teaching practices. For example, in one interview, Aisha described the importance of teachers "meeting children where they are" and "making connections to children's outside of school experiences". Yet her classroom practices reflected obliviousness if not disregard for children's prior mathematical knowledge. Analysis of all her videotaped lessons revealed Aisha had incorporated none of the rubric categories associated directly with CR. And although in interviews she expressed support for teaching "outside the box", on multiple occasions during post-teaching reflections Aisha shared that her reason for teaching particular lessons was because they appeared in the district guide. Such explanations contrasted sharply with the dispositional image we had come to associate with Aisha. Based on that image, we expected Aisha to offer that her selection of any given lesson was based on her judgment of its potential to make effective use of or connections with students' extant mathematics knowledge.

One-on-one interview data did not reconcile the instances of initiation we uncovered across our diverse data sources of Aisha's teaching and reflections thereon. Instead, we identified additional supporting evidence of the initiation phenomenon that contradicted the dispositional stance toward CR we assumed was hers. Indeed, interview data revealed a different side to Aisha's perceptions of CR --- one that seemed aligned with "culture of poverty" explanations for academic underachievement and school failure among ethnoracial minority and economically impoverished students. Gorski (2005) identified ideas propagated through the publications and teacher workshops of Ruby Payne as contributing to the pervasiveness of this deficit orientation. Through isolating Aisha's interview comments coded as the CR sub-skill cultural referencing we found additional evidence of her interpretations of CR in the interview context that were out of alignment with understandings she expressed during retreats. A recurring deficit theme was apparent in several of Aisha's references to the cultural backgrounds of the children in her class/school. The following comment is illustrative.

Socioeconomic status has an effect on everything. Because they [children from economically poor families] tend to be underexposed for things that schools measure and value and appreciate. But over-exposed for things that are not age-appropriate. So they know things. But they're not things 
that they should necessarily know.

Interestingly, Aisha interspersed such input with ideas that do align with $\mathrm{CR}$ and with ideas she expressed in retreats. In this regard, to the above statement she seamlessly added, "So you have to find a way to start with what they know." Nevertheless, more commonly her interview responses were suffused with stereotypical descriptions of the home lives of children from economically stressed families and environments. The following is another instance of the cultural referencing interview code.

And the economic status comes into play because a lot of people in, I'll say poverty for, you know, interview's sake, that they don't talk to their kids. They talk at their kids. So the vocabulary's limited. A lot of times there are expletives used. .... people tend to give their kids orders. There's not a lot of conversation.

In the midst of the above segment, Aisha seemed to experience a brief moment of critical awareness that she was stereotyping children who, in the context of retreats, she had acknowledged as being underserved by teachers. Thus, she noted, "not as a generalization, but just the stress of the day-to-day keeps the parents from doing some of the things that they really need to do." Yet, this comment was immediately followed with more deficit, stereotype-laced description of how such children present in the classroom context.

So the kids may know what money is, that's one of the discussions [that] came up, counting money. ... They don't understand, you know, some of the one-to-one correspondence because nobody talks to them. They talk at them. Don't spend time with them. Not because they don't want to; but because they don't have the time.

This comment exposed a chilling irony when we considered that one-to-one correspondence represents an early mathematics concept that, for most kindergartners, is first encountered at school rather than home. Hence, it easily falls within the realm of topics about which teachers (rather than parents) would be expected to talk "to" or "at" children with the goal of establishing a firm foundation for study of more complex concepts such as sorting and graphing.

\section{DISCUSSION}

The case of Aisha represents a cautionary tale for teacher educators about challenges of conducting professional development research to promote understanding and implementation of critical pedagogies among practicing classroom teachers. It offers a particularly important lesson to those among us 
inclined to presume certain connections between ideology and practice. On the one hand, Aisha understood and endorsed CR as a pedagogical orientation consistent with her own professional stance. Yet on the other hand, we found scant evidence of the CR sub-skills highlighted in our project in videotape playbacks of her teaching. What happened (or did not happen) in her actual teaching interactions with the kindergarteners, however, was not the central confounding issue that captured our attention. Rather, the case of Aisha is noteworthy because of striking disconnections and contradictions between reflections on her teaching, and the multiple evidences of dispositions in support of CR that she consistently and convincingly presented.

We believe Aisha was sincere about her attitudes and beliefs as articulated in the project retreats. In our judgment they were in alignment with $\mathrm{CR}$ and as such, we remain convinced that on the whole Aisha possesses an outlook that would permit her to enact a critical pedagogy in an appropriately supportive professional environment. Even so, we now recognize that this was only part of Aisha's story. The other more impactful part, which is an advisory to other teacher educators, is represented by Aisha's response to our repeated challenge for her (and the other teachers in our study) to demonstrate the ability to recognize and reconcile (if only through reflective hindsight) what can be characterized as an "ill-structured" pedagogical problem.

\section{ILL-STRUCTURED PROBLEMS LEADING TO PROFESSIONAL PARALYSIS}

High quality teaching constitutes intense intellectual work that increasingly is characterized by a plethora of problems for which teachers are charged to identify and implement solutions in the form of effective instructional practices. The challenge to find solutions can be complicated by issues in the workplace and/or by teacher's own orientations toward problem solving. Additionally, the quality of teachers' pedagogical problem solving capabilities can be impacted by their knowledge of and comfort with curricular content. In schools where the professional climate is buttressed by any number of high-stakes variables, teachers are likely to find that many of the pedagogical problems they encounter are highly complex and multi-dimensional. Kitchner and King (1990) labeled these problems as real world or "ill-structured". Such problems have enormous potential to stymie the efforts of even the most secure teachers because "... all the parameters are seldom clear or available [thus making it] ... difficult to determine when and whether an adequate solution has been identified." (p. 164). Similarly, solutions for ill-structured problems are often "based on incomplete information or evidence that is subject to multiple interpretations..." (King \& Kitchener, 2002 , p. 56). Based on our collective experience across all pre-collegiate grade levels, teachers are far less confident in their abilities to identify viable solutions for ill-structured pedagogical problems. This is particularly so when the problem presents in conjunction with teaching students from diverse cultural backgrounds. 
Instead, such problems aggravate professional vulnerabilities and they promote reversion to perceived tried and true practices. Often, the teacher's inability to immediately generate alternative workable solutions to the ill-structured problem promotes an inclination to turn to authorities for solutions (King \& Kitchener, 2002).

The challenge we presented to Aisha and the other teachers in our study was to enact a culturally relevant pedagogy in relation to early mathematics. For many of our teachers, this multi-dimensional challenge may well have represented an ill-structured problem of the highest magnitude. Initially, it required the teachers to be secure in their own understanding of the K-2 mathematics curriculum. Next, the challenge emphasized teaching with the aim of promoting deep understanding by aligning (to the extent possible) pedagogical practices with children's extant mathematical knowledge. A third component of the challenge was to articulate what it means to "understand" the mathematical ideas. In conjunction with this, the teachers had to analyze and evaluate their own instructional practices to determine whether they were promoting or hindering successful outcomes (i.e., "understanding") for children. Through reflection on their teaching some recognized the need to abandon extant teaching practices as well as pedagogical problem solving orientations with which they had become comfortable.

In the case of Aisha, the multi-tiered reflection challenge had a paralyzing effect rendering her unable to draw upon values and apply knowledge she clearly embraced as part of her professional identity. Consequently, in both her teaching and her reflections on practice, Aisha resorted to "tried and true" techniques and explanations that intimated an inability to make effective learning connections for children, and to think deeply and critically about the impact of her pedagogy on children's mathematical learning. Reverting to the "tried and true" may have offered Aisha personal comfort and a temporary sense of security about her practice, yet analysis revealed her reflections to be diametric to other attitudes and beliefs she had repeatedly presented in the project retreats.

\section{So What CAN Dispositions Tell Us, REALly?}

In 2000, the National Council for the Accreditation of Teacher Education revised its standards and "unleashed a feisty debate on the role of dispositions in teacher preparation" (Borko, et al., 2007, p. 359). The debate prompted introspection among teacher education scholars (Johnson \& Reiman, 2007; Kidd, et al., 2008) while at the same time it provoked dismissive commentary from teacher education critics (Leo, 2005; Will, 2006). Much of the debate centered on the vexing question what is a disposition? Murray (2007) offered probably the most austere response by suggesting that disposition is a "superfluous construct". Chiding teacher educators he noted "[t]he field of education is littered with terms, neologisms, and jargon that turn out under examination to have limited meaning, 
despite their conveying an impression that something is known and explained" (pp. 381-382). In direct contrast, however, Hoadley and Ensor (2009) opined "dispositions... refer to relatively stable orientations informing practice. These are...propensities that inform judgments" (p. 879). The latter part of their interpretation captures the essence of the beliefs/practice congruence we sought to promote among the K-2 teachers in our study.

From the outset we recognized that identifying and promoting professional dispositions would be an exceedingly difficult challenge for us, and that the difficulty quotient would be compounded by our focus on cultural relevance and its integration with early mathematics teaching and learning. We anticipated that to some extent, the difficulty would be owing to the multiple interpretations of what constitutes CR (Young, 2010) and the fact that as a construct CR has been theorized in a manner that largely portends incompatibility with operationalization into discrete component parts or what some might see as prescriptions. For example, Ladson-Billings (1995) described her propositions as structured to "avoid an essentialized and/or dichotomized notion of the pedagogy of excellent teachers" (p. 478). Earlier she had noted, "culturally relevant teaching is not a series of steps that teachers can follow or a recipe for being effective with African American students" (Ladson-Billings, 1994, p. 26). This disinclination to identify "the" way to do cultural relevance for most if not all of the teachers in our study contrasted sharply with previous professional development they had experienced, expected, and perhaps come to depend on. We attempted to meld the two stances by identifying CR sub-skills that we theorized could be incorporated into a primary-grade instructional repertoire without compromising the critical essence of the overarching CR tenets. Despite our efforts, many of the teachers remained confounded by how to begin incorporating $\mathrm{CR}$ into their mathematics pedagogy. And through Aisha we discovered that the resolve of even a teacher who consistently demonstrates high-level knowledge about and a favorable propensity to enact $\mathrm{CR}$ pedagogy might collapse under the weight of a challenge to incorporate it into her practice. Thus, it may well be that without a greater degree of prescription in the context of professional development even would-be implementers will interpret $\mathrm{CR}$ as an exceedingly theoretical, vague, and amorphous construct.

The case of Aisha has prompted us to pose questions about promoting CR in early mathematics instruction, and the usefulness of highlighting teacher dispositions toward $\mathrm{CR}$ as an indicator of a likely pedagogical integration. Our most sobering query has been, what can a positive disposition toward CR tell us, really? To gain insights on this we turned a critical lens on our reading of the data for the period Aisha was in our study. We recognized that due to interruptions in our research schedule and changes in our research team, early on our reading of the data was intermittent. Consequently, it was not until the end that we realized we had conflated Aisha's own sociopolitical awareness of issues surrounding racism, inequality, and historic black devaluation in the larger society, with her 
ability to create effective learning moments for children vis-à-vis early mathematics. In short, we assumed that because Aisha, as an African American teacher, exhibited ability to unpack the workings of racism and inequality in schools, this would transfer into a critical pedagogy in her own teaching context. Thus, it appears Aisha's exhibited dispositions reflected more her readiness to critique the larger context in which schools operate rather than her specific actions as a teacher therein.

\section{CONCLUSION: LESSONS LEARNED FROM THE CAUTIONARY TALE}

Reflections on NMD heightened our sensitivity to the fragility of the concept "professional dispositions" as a useful indicator of the pedagogy a teacher is likely to implement in any given curricular context. Aisha's exhibition of "requisite professional dispositions" was refreshing but ultimately it proved perplexing. Hence the case of Aisha represents a cautionary tale that challenges us to critique the substance of would be insights gained --- outside the real world context of classrooms --- about a teacher's orientations toward teaching. We take away three lessons from this tale that we believe can be useful for others.

First, ill-structured, multi-tiered pedagogical problems might predispose some teachers, who otherwise are inclined to incorporate critical orientations in their practice, to adopt or revert to simplistic non-critical solutions. This might be particularly so when the problem exposes an area of professional vulnerability for the teacher. Contradictions between beliefs and practice may result from the teacher's effort to reconcile conflicting images of the professional self that are revealed in such situations. For Aisha, a component of the professional problem we presented inadvertently represented an on-going threat to her identity as a culturally relevant teacher. Her reflection on the NMD experience in the focus group highlighted this when she noted, “... it wasn't the culture piece I struggled with. I struggled with the math piece". We did not anticipate the level of challenge shoring up her mathematics content and pedagogical knowledge represented, yet it appears that for Aisha, the notion of promoting "deep mathematical understanding" was both a professional and personal challenge.

Second, professional development that includes reflection on practice needs to be structured to help teachers recognize and unpack contradictions between their professed beliefs, their teaching practices, and their explanations for those practices. To avoid anxieties the teachers may have experienced if we had facilitated the reflection sessions, we assigned this task to our project RAs. This turned out to be a limitation of our study, however, as the RAs did not engage in the more complex level of facilitation that was clearly warranted in the case of Aisha. Analysis of the transcripts revealed she was never challenged to reconcile the inconsistencies between her reflection comments and the insights she shared 
during retreats. One likely reason for this is the RA may have been unaware of dispositions Aisha exhibited during retreats. Our RAs were not required to attend the project retreats except to set up materials; therefore, they had limited knowledge of the teachers' contributions to those sessions. Had we led the reflection sessions, we could have supported Aisha in reconciling the glaring disconnections between the dispositions she demonstrated in retreats and reflections on her teaching.

Finally, we fully expected to see elements of cultural relevance in Aisha's pedagogy. In hindsight we acknowledge the sense of certainty we assumed about our assessment, to no small degree, was based on the fact that Aisha is African American and she exhibited a healthy black reference-group identity (Helms, 1993). The value added nature of her racial identity coupled nicely with the critical sensibilities about race and culture she demonstrated, which we expected would promote critical self-reflection about her practice. Even so, we did not assume that the value added impact of Aisha's cultural and racial sensibilities alone would portend the nature of her pedagogy. Indeed, there were other black women in our study for whom we did not hold similar expectations. Moreover, Villegas and Davis (2008) put it well when they noted, [w]hile the cultural knowledge [Blacks] bring to teaching gives them an advantage over their White colleagues ... it would be simplistic to assume [Blacks] can become culturally responsive educators on their own" (p. 597). We made sure the teachers in our study were not on their own. Indeed, Aisha seemed especially supported because in addition to our backing, she was buoyed by the exciting confluence of critical cultural consciousness and a graduate degree with a focus in diversity. She had facilitated professional development for other teachers and saw herself as a culturally relevant pedagogue. Thus, the tale of Aisha exposed our subjectivities and challenged our most basic assumptions about how race operates in the teaching-learning process, and its prominence in teacher education discourse. The lesson we take is that a teacher's awareness of structural inequities and sociopolitical issues in the larger society may not position her to enact pedagogy with substantive potential to counteract the manifestations of these factors in the classroom. Hence, as was suggested by some of our teachers, the theory of cultural relevance may demand far greater concretizing to promote its transfer to the real world context of primary grades in general, and early mathematics teaching in particular.

\section{REFERENCES}

Borko, H., Liston, D. \& Whitcomb, J. A. (2007). Apples and fishes: The debate over dispositions in teacher education. Journal of Teacher Education, 58(5), 359-364.

Brown, E. L. (2004). What precipitates change in cultural diversity awareness during a multicultural course: The message or the method? Journal of 
Teacher Education, 55(4), 325-340.

Coffey, A., \& Atkinson, P. (1996). Making sense of qualitative data: Complementary research designs. Thousand Oaks, CA: Sage.

DeCuir-Gunby, J. T., Marshall, P. L., \& McCulloch, A. W. (2012). Using mixed methods to analyze video data: A mathematics teacher professional development example. Journal of Mixed Methods, 6(3), 199-216. . (2011). Developing and using a codebook for the analysis of interview data: An example from a professional development research project. Field Methods. 23(2),136-155.

Franke, M. L., Kazemi, E., \& Battey, D. (2007). Understanding teaching and classroom practice in mathematics. In F.K. Lester, Jr. (Ed.) Second Handbook of Research on Mathematics Teaching and Learning (pp. 225256). Charlotte, NC: Information Age Publishing.

Gay, G. (2002). Preparing for culturally responsive teaching. Journal of Teacher Education, 53(2), 106-116.

Giroux, H. A. (2005). Border crossings: Cultural workers and the politics of education. 2nd edition. New York: Routledge.

Gorski, P. C. (2005). Savage unrealities: Uncovering classism in Ruby Payne's framework. EdChange. http://www.Edchange.org.

Greene, J. C., Caracelli, V. J., \& Graham, W. F. (1989). Toward a conceptual framework for mixed-method evaluation designs. Educational Evaluation and Policy Analysis, 11(3), 255-274.

Haberman, M. (1995). Star teachers of children in poverty. West Lafayette, IN.: Kappa Delta PI.

Helms, J. E. (Ed.). (1993). Black and white racial identity: Theory research and practice. Westport, CT: Praeger.

Hiebert, J., Carpenter, T. P., Fennema, E., Fuson, K. C., Wearne, D., Murray, H., et al. (1997). Making Sense: Teaching and learning mathematics with understanding. Portsmouth, NH: Heinemann.

Hoadley, U. \& Ensor, P. (2009). Teachers' social class, professional dispositions, and pedagogic practice. Teaching and Teacher Education, 25, 876-886.

Hodge, L. L. \& Cobb, P. (2010, April). Two views of culture and their implications for mathematics teaching and learning. Paper presented at the Research Pre-session meeting of the National Council of Teachers of Mathematics, Denver, CO.

hooks, b. (1994). Teaching to transgress: Education as the practice of freedom. New York: Routledge.

Irvine, J. J. (1990). Black students and school failure. New York: Praeger.

Johnson, L. E. \& Reiman, A. J. (2007). Beginning teacher disposition: Examining the moral/ethnical domain. Teaching and Teacher Education, 23, 676-68.

Kidd, J. K, Sánchez, S. Y., Thorp, E. K. (2008). Defining moments: Developing Culturally responsive dispositions and teaching practices in early 
childhood preservice teachers. Teaching and Teacher Education, 24, 316329.

Kincheloe, J. L. (2005). Critical constructivism primer. New York: Peter Lang.

King, P. M. \& Kitchener, K. S. (2002). The reflective judgment model: Twenty years of research on epistemic cognition. In B. K. Hofer and P. R. Pintrich (Eds.). Personal Epistemology: The Psychology of Beliefs about Knowledge and Knowing. (pp. 37-61). Mahwah, NJ: Lawrence Erlbaum \& Associates Publishers.

Kitchener, K. S. \& King, P. M. (1990). The reflective judgment model: Transforming assumptions about knowing. In J. Mezirow \& Associates (Ed.). Fostering Critical Reflection in Adults: A guide to transformative and emancipatory learning. (pp. 159-176). San Francisco: Jossey-Bass Publishers.

Ladson-Billings, G. (1994). The dreamkeepers: Successful teachers of African American children. San Francisco: Jossey-Bass. . (1995). Toward a theory of culturally relevant pedagogy. American Educational Research Journal, 32(3), 465-491.

Leo, J. (2005, October 16). Class(room) warriors. U.S. News \& World Report. Retrieved April 12, 2010, from http://www.usnews.com/usnews/opinion/articles/051024/24john.htm.

Marshall, P. L. (2002). Cultural diversity in our schools. Belmont, CA: Wadsworth.

Murray, F. B. (2007). Disposition: A superfluous construct in teacher education. Journal of Teacher Education. 58(5) 381-387.

Nasir, N. S., Hand, V. \& Taylor, E.V. (2008). Culture and mathematics in school: Boundaries between 'cultural' and 'domain' knowledge in the mathematics classroom and beyond. In J. Green, G. J. Kelly, \& A. Luke (Eds.), Review of Research in Education (Vol. 32:1 pp.187-240). Washington, DC: American Educational Research Association.

National Council of Teachers of Mathematics (2000). Principles and standards for school mathematics. NCTM: Reston, VA.

Noguera, P. (2001). Racial politics and the elusive quest for excellence and equity in education. Education and Urban Society, 34:1, 18-41.

Orfield, G. \& Lee, C. (2006). Racial transformation and the changing nature of segregation. Cambridge, MA: Harvard University Civil Rights Project.

Palincsar, A. S. (1998). Social constructivist perspectives on teaching and learning. Annual Review of Psychology, 49, 345-375.

Phinney, J. S. (1993). A three-stage model of ethnic identity development in adolescence. In M.E. Bernal and G. P. Knight (Eds.), Ethnic identity: 
Formation and transmission among Hispanics and other minorities (pp. 61-79). Albany: SUNY Press.

Polkinghorne, D. E. (1995). Narrative configuration in qualitative analysis. International Journal of Qualitative Studies in Education, 8(1), 5-23.

Rossman, G. B. and Wilson, B. L. (1985). Numbers and words: Combining quantitative and qualitative methods in a single large-scale evaluation study. Evaluation Review, 9(5), 627-643.

Rossman, G. B. and Wilson, B. L. (1994). Number and words revisited: Being shamelessly eclectic. Quality and Quantity, 28(3), 315-327.

Rubin, H. J. \& Rubin, I. S. (2005). Qualitative interviewing: The art of hearing data. ( $2^{\text {nd }}$ ed.). Thousand Oaks, CA: Sage.

Simon, M.A., Tzur, R., Heinz, K., Kinzel, M., and Smith, M.S. (2000).

Characterizing a perspective underlying the practice of mathematics teachers in transition. Journal for Research in Mathematics Education, 31(5), 579-601.

Sleeter, C. E. (2008). Preparing white teachers. Teachers of color. In M. CochranSmith, S. Feiman-Nemser, D. John McIntyre, \& K. E. Demers (Eds). Handbook of Research on Teacher Education ( $3^{\text {rd }}$ edition) (pp. 559-582). New York: Routledge/ Taylor \& Francis Group \& The Association of Teacher Educators.

Stigler, J.W., Gonzales, P. Kawanaka, T., Knoll, S. \& Serrano, A. (1999). The TIMMS videotape classroom study: Methods and findings from an exploratory research project on eighth-grade mathematics instruction in Germany, Japan, and the United States. Washington, DC: National Center for Educational Statistics.

Villegas, A. M. \& Davis, D. E. (2008). Preparing teachers of color. In M. Cochran-Smith, S. Feiman-Nemser, D. John McIntyre, \& K. E. Demers (Eds). Handbook of research on teacher education ( $3^{\text {rd }}$ edition) (pp. 583-605). New York: Routledge/Taylor \& Francis Group \& The Association of Teacher Educators.

Will, G. F. (2006, January 16). Ed Schools v. education. Retrieved on April 12, 2010, from

http://www.msnbc.msn.com/id/10753446/site/newsweek/print/1/displaymode/10 98.

Yin, R. K. (2004). The case study anthology. Thousand Oaks, CA: Sage.

Young, E. (2010). Challenges to conceptualizing and actualizing culturally relevant pedagogy: How viable is the theory in classroom practice. Journal of Teacher Education, 61(3) 248-260. 